\title{
TRIBUTE \\ The American Society of Pediatric Hematology/Oncology Distinguished Career Award Goes to Laurence A. Boxer, MD
}

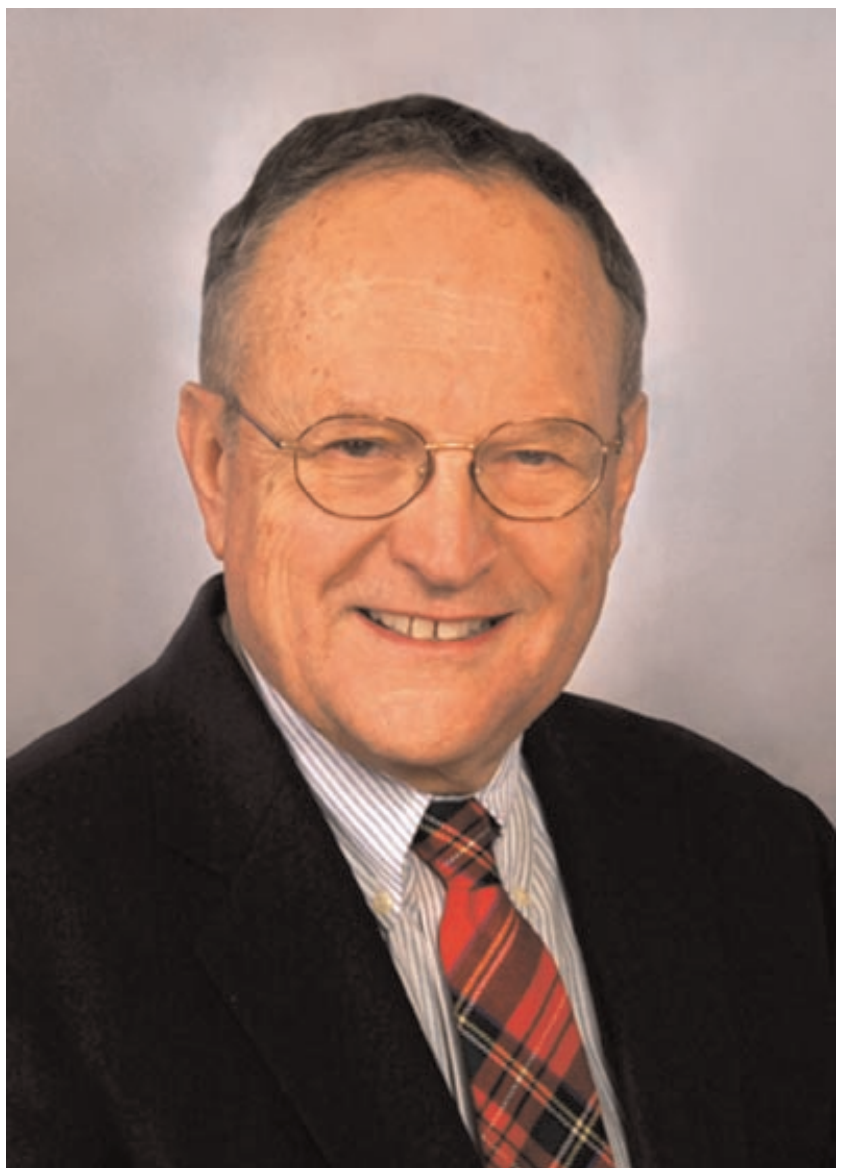

Laurence A. Boxer, MD, this year's recipient of the Distinguished Career Award from the American Society of Pediatric Hematology/Oncology, is a leader in pediatric hematology/ oncology with a long career marked by accomplishment and leadership in research, training, and patient care, as well as exceptional service to ASPHO and other scientific societies.

Larry was born in Denver in 1940 to Sam and Tillie Boxer, the eldest of their three boys. Sam and Tillie ran a mom and pop plumbing operation, Belmont Plumbing, starting when Denver was a relatively small town.

Larry attended East High School in Denver. His brother Mike recalls, "The time was the '50s and the school was right out of 'American Graffiti.' Larry was on student council and very popular in school. He was accepted to attend Yale University, but took a scholarship he was awarded to the University of Colorado," graduating in 1961, magna cum laude in history.

Larry made many life long friends at Colorado and the Phi Sigma Delta fraternity. His brother Mike writes, "Many of his fraternity brothers still talk about how he kept kosher while living in the fraternity house. It was widely believed that Larry was going to be a Rabbi." His father preferred that he enter the family business, but told Larry "if you cannot become a plumber, you can always become a doctor." Larry chose the latter and attended Stanford Medical School. Earlier this year, he was honored as the J. Wallace Sterling Outstanding Medical Alumnus of Stanford University.

After receiving his M.D. from Stanford University in 1966, he trained as a resident in pediatrics at Yale University from 1966 to 1968. There he met his wife, Grace, now a medical hematologist with whom he has collaborated on several research studies and publications. Their son David, born in 1976, is a teacher, information technologist, and social activist.

He returned to Stanford as a senior resident, from 1969 to 1972 and served his Vietnam-era military duty as a pediatrician at the Tripler Army Hospital in Honolulu, an experience that he fondly recalls to have sparked a lifelong affinity for the Hawaiian Islands.

From 1972 to 1975 he was a fellow and then an instructor in hematology at Children's Hospital Boston, and Harvard Medical School. In 1975, he was appointed Assistant Professor of Pediatrics at Indiana University School of Medicine and became a Professor of Pediatrics in 1982. That same year he moved to Ann Arbor, Michigan where he assumed the position of Professor and Director of the Division of Pediatric Hematology/Oncology at the University of Michigan, where he has also served as Associate Chair for Research and subsequently for Faculty Affairs. In 2003 he was named to the Henry and Mala Dorfman Family Chair in Pediatric Hematology/Oncology, a Professorship established in part to recognize the extraordinary care provided by Larry to two of the Dorfman children. Larry has just retired as director of the pediatric hematology/oncology division, but will continue his considerable efforts in research, teaching, and patient care.

Larry has received national and international recognition for his success as a physician-scientist, clinician, and teacher. He has served as a councilor of the Society for Pediatric Research (19821985), the American Society of Hematology (1988-1992) and the American Pediatric Society (2001-2006), and was elected president of the Society for Pediatric Research (1985-1986). His research accomplishments have been recognized with the Pediatric Academic Societies' highest recognition for research, the Mead Johnson Award (1983). In 1997, Larry was elected a fellow of the American Association for the Advancement of Science and in 1998, he received the Founder's Award from the Midwest Society for Pediatric Research. Larry has also been elected to the American Society of Clinical Investigation and the American Association of Physicians, and serves as a founding section editor for $H E M / O N C$

*Correspondence to: Peter E. Newburger, Department of Pediatrics and Cancer Biology, University of Massachusetts Cancer Center, 364 Plantation Street, LRB 404, Worcester, MA 01605.

E-mail: peter.newburger@umassmed.edu

Received 13 February 2008; Accepted 13 February 2008 
TODAY - these particular honors indicate the esteem with which he is regarded by our colleagues in internal medicine and medical oncology.

Larry has worked in many other editorial positions, including associate editor for the Journal of Clinical Investigation and the American Journal of Hematology. He has served on multiple editorial boards - including, at the present time, Current Opinion in Hematology, Hematotherapy and Stem Cell Research, Pediatrics in Review, Pediatric Blood and Cancer, and American Journal of Hematology - and is currently a member of the ASH Publications Committee.

In ASPHO, Larry currently serves as a trustee and member of the Executive Board. As a member and then chair of the Publications Committee, he played an instrumental role in the establishment of this journal. Larry also helped organize and teach the highly successful board review course.

Larry's research has focused on disorders of phagocyte number and function. His laboratory research has received continuous support by the National Institutes of Health since 1976. His contributions include major discoveries in the pathology, molecular biology, and treatment of phagocyte disorders including ChédiakHigashi syndrome, secondary granule deficiency, and chronic granulomatous disease, as well as fundamental investigations into the biochemistry of neutrophil phagocytosis, granule sorting, and exocytosis. His clinical research in neutropenia included important clinical trials of G-CSF for congenital neutropenia and, through his leadership role in the Severe Chronic Neutropenia International Registry, influential and ongoing investigations of the molecular basis of congenital neutropenia and the risks of myelodysplasia and AML in G-CSF-treated patients.

Although Larry did not follow his early inclination to be a rabbi, he definitely became a teacher. Junior faculty members and fellows (over 35 to date) who have trained or established their early careers under Dr. Boxer's mentorship now lead major academic programs, are corporate officers in pharmaceutical giants, or deliver worldclass care in clinical programs and major academic medical centers. Several have become division directors or hold endowed chairs, one heads a research division within the $\mathrm{NIH}$, and one chairs a department of pediatrics. Importantly, he is a strong advocate for encouraging trainees to develop careers in benign hematology-a field that certainly can use more practitioners. Larry has lectured nationally and internationally, including invitations to endowed lectureships at leading universities in the United States, Canada, The Netherlands, and Israel. Locally, in 2005 he was selected as one of the outstanding teachers for the house staff in the Department of Pediatrics at the University of Michigan.

Larry's expertise and compassion in patient care have led to his citation in The Best Doctors in America since 1994. Patients and families seek his advice, particularly in the management of neutropenia, from throughout the nation and the world. In addition to his fundamental clinical research on the efficacy of G-CSF in the treatment of severe chronic neutropenia, he was an early and effective advocate in encouraging Amgen Pharmaceuticals to provide the drug at no cost for patients in the International Registry. Larry has been a speaker at family support groups for neutropenia for many years and hosted the annual neutropenia family meeting in Ann Arbor this past July. He has also advocated for young adults' access to cancer clinical trials and for manpower to care for children with benign hematological disorders.

Larry's extraordinary record of achievement and commitment to our discipline and to ASPHO are matched by his incredibly warm, engaging and friendly demeanor that is cherished by all who have had the pleasure to work with him over the years. Certainly "distinguished career" most appropriately describes his contributions to the field of pediatric hematology/oncology and to his many patients, colleagues, and students.

Peter E. Newburger, MD* Departments of Pediatrics and Cancer Biology University of Massachusetts Medical School Worcester, Massachusetts 01655

Valerie P. Castle, MD Departments of Pediatrics and Communicable Diseases University of Michigan Medical School Ann Arbor, Michigan 48109 